\title{
Synthesis and Characterization of L-Arginine $\mathrm{H}_{3} \mathrm{PO}_{4}$ Nano-Crystals with Non- Linear Optical Properties.
}

\author{
J. Hernández Paredes ${ }^{1}$, H. Esparza Ponce ${ }^{1}$ and A. Duarte Moller ${ }^{1,2}$ \\ ${ }^{1}$ Centro de Investigación en Materiales Avanzados, S. C. \\ Miguel de Cervantes 120, Complejo Industrial Chihuahua \\ Chihuahua, Chih. 31109, México \\ ${ }^{2}$ Departamento de Física, Universidad de Sonora, Blvd. Rosales s/n \\ Hermosillo, Son., 83000, México
}

Crystals of L-Arginine $\mathrm{H}_{3} \mathrm{PO}_{4}$ with potential non-linear properties have been grown from aqueous solution by slow evaporation method at room temperature and controlled $\mathrm{pH}$. These Crystals were characterized by UV-VIS, FTIR, AFM and XRD powder diffraction technique. Ultraviolet-Visible, show a highly transparent window to $275-1100 \mathrm{~nm}$. Infrared, IR spectra confirm the chemical constituents and functional groups are present in the crystals [1] and AFM technique confirm their sizes around $20 \mathrm{~nm}$. A discussion about the atomic and electronic structure and its simulation are presented here.

The reagents used for the preparation of the LAP solution were: L-Arginine $\left(\mathrm{C}_{6} \mathrm{H}_{14} \mathrm{~N}_{4} \mathrm{O}_{2}\right)$ Faga Lab of a purity of $99.6 \%$ and $\mathrm{PM}=174.20$, and fosforic acid ( $\left.\mathrm{H}_{3} \mathrm{PO} 4\right) \mathrm{J} . \mathrm{T}$-Baker at $85.1 \%$. The first solution was prepared with $50 \mathrm{~mL}$ of distilled water, $10,5 \mathrm{~g}$ of L-Arginine and $4.9 \mathrm{~mL}$ of $\mathrm{H}_{3} \mathrm{PO}_{4}, \mathrm{pH}$ of the solution of L-Arginine was of 11,3 and at the time of adding $\mathrm{H}_{3} \mathrm{PO}_{4}$ 2.6. the reason of the second distilled solution was of $50 \mathrm{~mL}$ of water, $10,5 \mathrm{~g}$ of L-Arginine and $3.1 \mathrm{~mL}$ of $\mathrm{H}_{3} \mathrm{PO}_{4}, \mathrm{pH}$ of the solution of L-Arginine was of 11,3 and at the time of adding the $\mathrm{H}_{3} \mathrm{PO}_{4}$ change to 4,3 both systems they stayed in constant agitation during the preparation, once ready were let rest to room temperature, soon when appearing formation of small crystals retirement a drop and placed in microscope substrate, observed the formation of a gel in the equal solution of $\mathrm{pH} 2.6$

The possible reaction that happens is the following one:

$\mathrm{NH}_{2} \mathrm{NHCNH}\left(\mathrm{CH}_{2}\right)_{3} \mathrm{CH}\left(\mathrm{NH}_{2}\right) \mathrm{COOH}+\mathrm{H}_{3} \mathrm{PO}_{4} \rightarrow\left(\mathrm{NH}_{2}\right)_{2} \mathrm{CNH}\left(\mathrm{CH}_{2}\right)_{3} \mathrm{CH}\left(\mathrm{NH}_{3}\right)+\mathrm{COO}-\mathrm{H}_{2} \mathrm{PO}_{4}$

The growth method of nanocrystals by the evaporation technique at room temperature generated crystals LAP with a stable combination ionic amino acid-compound that was verified by using different techniques. FTIR in Fig. 1 shows the radical groups of the L-Arginine. Also the presence of a dipole molecule was confirmed $\left(\mathrm{COO}-, \mathrm{NH}^{3+}\right)$ that favored to the formation of the crystalline structure. Analyzing the spectra of UV-Vis [2] in Fig. 2 the material do not present electronic transitions, in the rank of 275 to $1100 \mathrm{~nm}$ which indicate that is a good candidate for non-linear effects under radiation of $1064 \mathrm{~nm}$. The thermal analysis shows to a maximum temperature of exhibition by 1 hour $120^{\circ} \mathrm{C}$ for LAP, in which the crystal present thermal stability and conserve their crystalline structure (Fig. 3), it is verified with the study by X-ray diffraction, Fig. 4, where the conservation of the initial crystalline structure of the crystal is detected. Figure 5 displays a simulation of the structure built starting from the parameters obtained by the X-ray diffraction and 
Rietveld fit. Finally in Figure 6 appears an AFM image of the LAP nanocrystal where is appreaciable its monolitic growth.

\section{References}

[1] Wei Wu, Cheng Ye and Dong Wang, Arkivoc, II: 59-69. 2003

[2] R. T. Bailey, et al. J. Phys D: Appl. Phys. 24:135-145 1991.

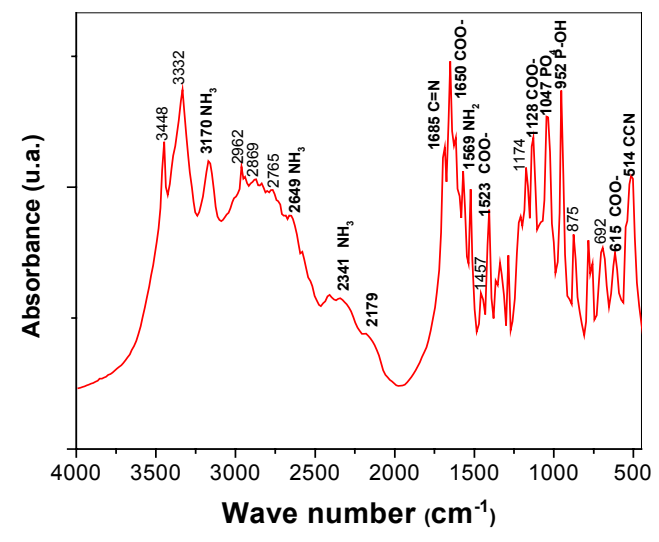

Fig. 1. IR spectrum of LAP showing its functional groups

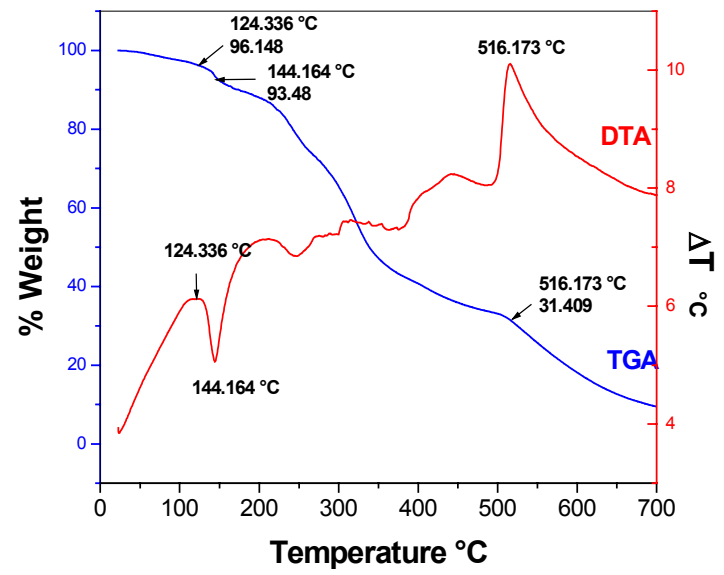

Fig. 3. DTA-TGA spectrum of LAP taken at 1hour

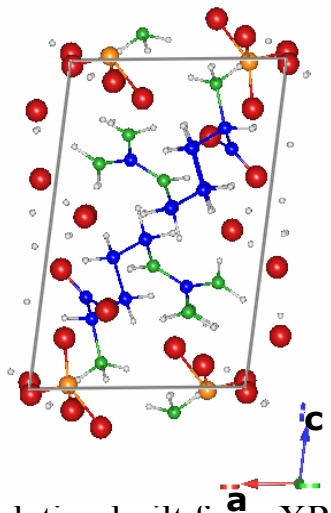

Fig. 5. Structure simulation built from XRD results shape

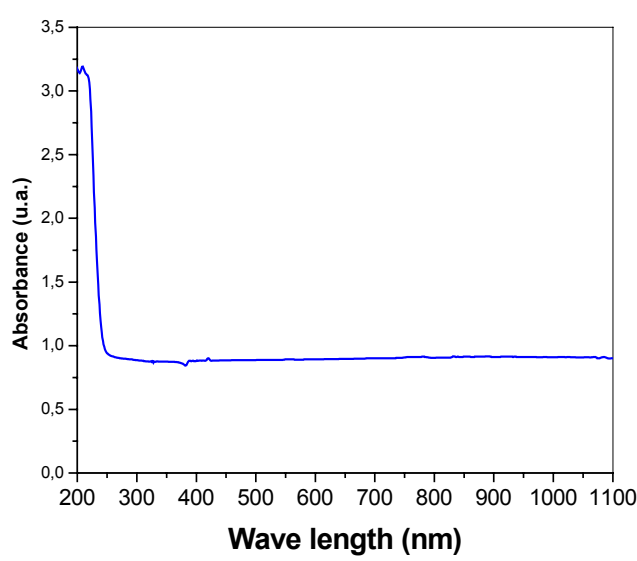

Fig. 2. UV-vis spectrum of LAP

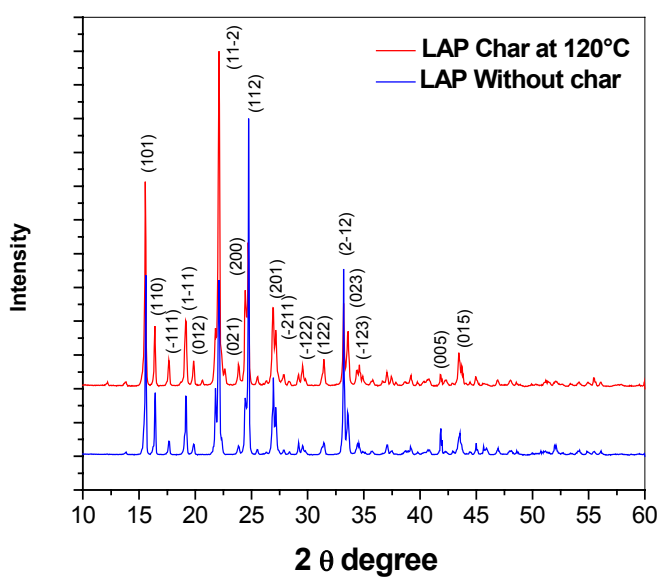

Fig. 4. A comparison between XRD patterns

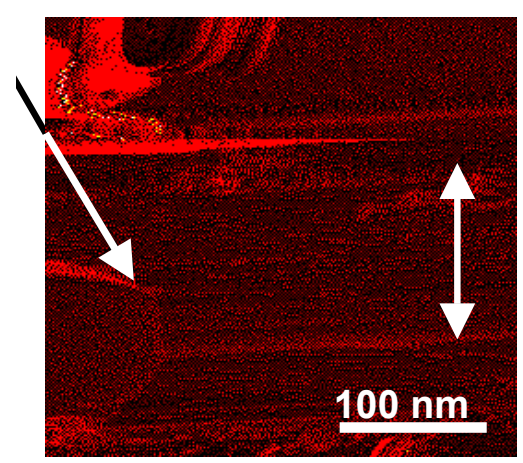

Fig. 6. AFM image of the LAP nanocrystals 